\title{
Issues for South Asian Indian Patients Surrounding Sexuality, Fertility, and Childbirth in the US Health Care System
}

Judith A. Fisher, MD, Marjorie Bowman, MD, MPA, and Tessie Thomas, DO

Background: In 1998 ethnic minorities comprised 28\% of the US population, and India is the third most common country of origin for immigrants. Many recently immigrated South Asian Indian patients are seen in health care settings in the United States. To deliver health care effectively to these patients, it is helpful for physicians to understand common cultural beliefs and practices of South Asian Indian patients.

Methods: Two illustrative cases are reported. One author's observations of the care of pregnant and parturient women in India and similar experiences in our own office spurred a literature search of the cultural behaviors surrounding sexuality, fertility, and childbirth. A literature search was conducted in Index Medicus, Grateful Med, and the catalogue of the University of Pennsylvania Arts and Sciences library, using the terms "Indian," "South Asian," "male and female gender roles," "gynecology in third world," "sexuality," "sexual health," "women's health," "women's health education," "obstetrical practices/India," and "female roles/India."

Results: Issues surrounding sexuality and childbirth that arise during the US physician - South Asian Indian patient encounter might not correspond to the commonly held knowledge, beliefs, and behaviors of the US health care system. Common cultural beliefs and behaviors of South Asian Indian patients around sexuality and childbirth experience include the role of the individual patient's duty to society, the patient's sense of place in society, lack of formal sexual education, prearranged marriages, importance of the birth of the first child, little premarital contraceptive education, dominance of the husband in contraceptive decisions, and predominant role of women and lack of role for men (including the husband) in the childbirth process.

Conclusion: Lack of understanding of the Indian cultural mores surrounding sexual education, sexual behavior, and the childbirth experiences can form barriers to Indian immigrants in need of health care. These misunderstandings can also lead to patient dissatisfaction with the health provider and health system, underutilization of health services, and poorer health outcomes for Indian immigrants and their families. For this reason, it is important to teach cultural issues during undergraduate, graduate, and continuing medical education. (J Am Board Fam Pract 2003;16:151-5.)

In 1998 ethnic minorities comprised $28 \%$ of the US population. ${ }^{1}$ Today many recognize the United States as a plurality, a country where the beliefs and behaviors of many cultures are cherished, practiced, and promulgated. To deliver health care effectively to all patients, it is important that physicians understand the intricacies of different cultural beliefs and practices. ${ }^{2}$ Nunez writes that "Clinicians must deal not only with such obvious cultural

Submitted, revised 1 May 2002.

From the Department of Family Practice and Community Medicine (JAF, MB), University of Pennsylvania, Philadelphia, and Continuum Health Services (TT), Beth Israel, St. Lukes Roosevelt, Philadelphia. Address reprint requests to Judith A. Fisher, MD, Department of Family Practice and Community Medicine, 6th Floor Mutch Bldg, 39th and Market Streets, Philadelphia, PA 19104. difference of their patients as language, dress, and diet, but also with more subtle cultural influences, such as the patient's perceptions of health, illness, and appropriate approaches to treatment." ${ }^{3}$

The March 2000 United States Immigration and Naturalization Service report described India as the third most common country of origin for immigrants. In fiscal year 1996 alone, 44,859 persons emigrated from India to the United States. ${ }^{4}$ Most $(83.8 \%)$ of these persons have achieved a high school degree or more $(86.6 \%$ of native-born Americans achieve a high school degree or greater). ${ }^{4}$ Those of Indian descent are entering the United States most often on work visas. While living in the United States, even the educated and accomplished Indian immigrant can find it chal- 
lenging to incorporate their native culture into that of his or her new Western, more liberal environment. In health care cultural dilemmas can prove challenging for those of Indian origin and their health care provider.

\section{Methods}

Two illustrative cases are reported. One author (TT), who is of South Asian Indian descent, delivered babies for 1 month in southern India. Her observations of the care of pregnant and parturient women and similar experiences in our own office spurred a literature search of the cultural behaviors surrounding sexuality, fertility, and childbirth. A literature search was conducted in Index Medicus, Grateful Med, and the catalogue of the University of Pennsylvania Arts and Sciences library, using the terms "Indian," "South Asian," "male and female gender roles," "gynecology in Third World," "sexuality," "sexual health," "women's health," "women's health education," “obstetrical practices/India," and "female roles/India."

\section{Sexual Education and Culture in India}

Health care cultural challenges can be particularly difficult in the arena of sexual health. Sexual health is very often considered a taboo subject in Indian families. ${ }^{5}$ Parents might foster their children's educational pursuits, but issues related to sexual health are often not discussed at home and believed to be important only "when the time comes." Asia's religions focus on female purity. A central religious tenet is that a family deliver a virginal bride. ${ }^{6}$ In Indian culture it is believed that prepubertal or pubertal girls do not have sexual impulses. The girls are secluded from nonfamilial men or are tightly chaperoned. On the other hand, it is thought that most men are not virgins at the time of their marriage and have had premarital sexual encounters with widows and deserted wives. ${ }^{6}$

Many, if not most, families believe that married couples will learn through experience or discuss sexual issues with their friends. In one study, Indian medical college students had learned their knowledge of sexual practices mostly from friends, pornographic books, films, and magazines. Only a small percentage of the students reported feeling comfortable talking about sex with their teachers, parents, or persons of the opposite sex. ${ }^{5}$ Students from one US medical school reported that $85 \%$ had read some literature on human sexual behavior. ${ }^{7}$

\section{Illustrative Cases \\ Case 1}

At her first office visit, a 37-year-old Asian Indian woman complained of "worsening of my chronic back problems." She had immigrated to the United States from India 11 years previously. On review of systems, her gynecologic history showed that the patient had menses every month for 4 to 5 days since her early teens and no pelvic pains or infections. She had never been pregnant nor had she used birth control of any type. For the past 9 years she was married and unable to conceive. She and her husband were currently undergoing a workup by an infertility specialist. On further questioning, it was discovered that she and her husband had never had sexual intercourse with penetration. The patient felt frightened and did not know what to do to overcome her fears. Initially, she was afraid to let her husband "do anything down there." At the time of this interview, her husband was having "difficulty with erections." The patient reported that she and her husband continued to have a good marital relationship. They hoped that the infertility specialist would decide to do artificial insemination or in vitro fertilization, as they felt an urgent need to produce a child.

The patient was a professional woman; her husband had a doctoral degree. Their marriage was arranged. Because she and her husband had been married for 9 years and had not produced any children, they were advised by their families to see an infertility specialist. Neither of their families (who lived in India) nor the infertility specialist knew that their marriage was unconsummated. The patient stated that she was embarrassed and ashamed about the situation.

On the initial visit the patient would not allow a pelvic examination. The importance of a female pelvic examination was discussed, and couples' counseling was recommended. The couples' counseling was vociferously rejected. Several visits later the patient asked her physician (JF) to do a pelvic examination and "one of those Papanicolaou tests." A pelvic examination was completed with gentleness and calm discussion of each step in the process. The patient was able to release the spasm of her vaginal muscles as her physician discussed breath- 
ing exercises and other relaxation techniques, pelvic anatomy, the steps involved in a pelvic examination with the Papanicolaou test, and the steps to full sexual intercourse.

The patient came to the office several weeks after her first pelvic examination. She was smiling. Her intent was to thank her family physician, because "the experience of the Papanicolaou test was so gentle and so educational" that she was able to go home and allow her husband to have sex with her. Both she and her husband were very happy. The patient was not yet pregnant, but they "were working on it" and considering adoption at the same time.

\section{Case 2}

During the first office visit a 25-year-old single, educated Asian Indian woman related a medical history of "I am positive for HPV." She answered no to both of the following questions: "Do you use birth control of any type?" and "Are you sexually active." Later in the visit she stated that she did use condoms. On subsequent visits for urinary tract infections or vaginal discharge, the patient again denied "having sex." After several years under our care, the patient admitted that her boyfriends did "do something to me down there." She thought that this was "part of what boyfriends do." On further questioning, the patient did not know how babies were conceived, what birth control was, or why she was asked about it. She did not like to do "this" with her boyfriends and did not know that she could refuse. After several other visits and discussions, the patient had started to tell her dates that she did not want to engage in sexual relations. Finally, she met a man she hoped to marry and asked whether it was true that birth control pills were good for acne. She wanted birth control pills for her acne. The patient hoped that "this man will marry me before next year as my parents [in India] say that they will arrange a marriage for me by next year."

\section{Discussion}

One of the authors, who is of Christian Indian descent (TT), spent a month in 2000 at Lakshmi Hospital in the town of Ernakulam in Kerala, India, caring for women and delivering babies. The experience proved enlightening and subsequently facilitated her care of Indian patients in the United
States. A literature search in the social science literature confirmed many of the ideas learned through first-hand experience.

In 1992 Nathawat and Mathur ${ }^{8}$ wrote: "Indian society is extremely complex, and its social and economic structures are significantly different from those in the Western industrial societies. India has remained largely agrarian and traditional despite decades of modernization efforts since its independence in 1947." As a result, in many parts of India today marriages are still arranged. ${ }^{9}$ Whereas a son or daughter is encouraged to grow up worrying about schooling or learning the family's business, occupation, or household needs, it is the duty of the extended family to plan for the individual's future, including marriage. The concept of single men and women independently planning for their own married life is not encouraged, because Indian culture stresses social duty as more important than individual rights. ${ }^{9}$ The caste system is still a major organizing institution in Indian society. ${ }^{6}$ Caste is a construct of the Hindu religion, but it remains a secular societal construct for Christians, Jains, Muslims, and Sikhs as well. Cross-religious and cross-caste marriages are not promoted and considered unacceptable. ${ }^{6}$

Although in many areas of India women are married in their teens, a changing society along with the access of education for many women has pushed the average age to 20 years. ${ }^{10,11}$ Men are married when they are aged 20 to 25 years. ${ }^{6}$ Despite the later age at marriage, many women are closely monitored. Many girls attend single-sex schools. ${ }^{6}$ Young women leave their homes escorted by a brother or in the company of other women. Among the young women, much discussion about boys is based on romantic fiction and movie plots. It is not acceptable for an unmarried couple to be seen in public, as this could spoil the female's reputation. Men have more freedom in their movements. ${ }^{9}$ Potential suitors first come with their parents to the unmarried young woman's home and are introduced to her parents. Only later are appropriate suitors introduced to the woman.

Today sexually active or pregnant unmarried women are not killed, as sometimes happened in the past, but they might be pressured to the point where they consider suicide. ${ }^{6}$ Illicit pregnancies are kept quiet, within the family, and very often attempts are made to secure a marriage with the father. ${ }^{6}$ If a hastily arranged marriage fails to take 
place, the pregnancy might be secretly terminated. As a result, there is a $90 \%$ illegal abortion rate despite abortion being legal in India. ${ }^{9}$

Much of Indian custom is family based. For a young woman, having premarital sexual relations can affect the social ranking of her entire family, including any unmarried siblings. ${ }^{6}$ These siblings might be considered unmarriageable, or in many instances, their marriages will require a much larger dowry. ${ }^{6}$ When families are arranging a marriage, they make sure the family that their son or daughter is marrying into has a good reputation, which can be translated to be no history of premarital pregnancies or premarital sex. ${ }^{9}$ In towns (as opposed to the rural areas) some love marriages and cross-caste marriages do occur. In these cases, parental agreement is still important and cross-caste marriages often take place between castes at a similar hierarchical level. ${ }^{9}$

For many Indian women, lack of sex education makes their intercourse experiences painful. ${ }^{12}$ Sexual encounters are taught to be a duty and are not meant to be pleasurable for the woman. Mothers teach their daughters that their role in life is to make their husbands happy and not to question. Men are not educated about contraception. ${ }^{9}$ Often neither men nor women understand the concept of ovulation and timing pregnancies. The exception might be Indian women who attend Pre-Cana (premarital instructions given to Catholic Indian couples) classes that teach sex education before marriage. Generally, women are not educated about contraceptive options until after the first child. For this reason most couples have their first child within the first year of marriage. ${ }^{11}$ The birth of a healthy first child is used to assure both families that the marriage is a good match and that the couple is in good health. ${ }^{11}$ If a child is not born after the first or second year of marriage, couples are commonly sent to fertility specialists.

Mothers frequently accompany pregnant women to physician visits; husbands do not. Only the nurse and physician attend a patient's delivery. Most Indian obstetricians are female. The woman's mother and other female relatives are usually close by for assistance with her personal needs. Childbirth education is not promoted, and most women do not know what to expect. Indian women are routinely given episiotomies and are rarely given pain medications. A laboring woman voicing any questions or requests is considered a problem pa- tient. Understandably, then, for many of these women childbirth is scary. Husbands usually come to the hospital or birth center, but they are not permitted to watch the delivery. If visiting during postpartum rounds, husbands leave the room for the wife's examination.

Studies show that Indian men do not desire to regulate their fertility. ${ }^{12}$ Contraceptive use by either themselves or their female partner depends on the man's willingness. Any attempt by a woman to influence this activity could invite accusation of infidelity, physical abuse, or even divorce. Many men believe that condoms are restrictive and reduce pleasure and thus, condoms are reserved for use with prostitutes, not wives. ${ }^{13}$

While caring for the female patient in case 1 , it became clear that her culture played a role in her infertility. At the University of Loyola Chicago, Domeena Renshaw, MD, has cared for 158 couples in the past 20 years for unconsummated marriages (Domeena Renshaw, MD, personal communication, 24 October 2001, Department of Psychiatry, Loyola University Chicago). While unconsummated marriages occur across all socioeconomic groups and cultures, Renshaw states that many of these patients are highly educated Americans who have immigrated from countries where there are arranged marriages and no formal sex education. Early survey data from Britain estimated that $1 \%$ of all couples attending an infertility clinic had not consummated their marriages. ${ }^{14}$

As illustrated in both cases, other issues surrounding sexuality and childbirth can arise for an Indian couple. These issues might not correspond with the knowledge, beliefs and behaviors of their new Western society. ${ }^{15}$ First and foremost, young women might have no education as to normal sexuality, sexual intercourse, birth control, or sexually transmitted diseases. Indian women can have great fear of sexual intercourse and related issues. Second, a young couple might shame their families if they do not produce a healthy infant within the first year of their marriage or produce a child out of wedlock. Birth control might be forbidden or at least until the first child is produced.

Pregnancy can be a frightening time for a young wife, especially if there are no female relatives available to coach her. In many American hospitals and birthing centers, it is the norm for the new father to be present at the birth of his child. Indian men might prefer to wait outside the room or stay away 
from the hospital during this time. Indian women, on the other hand, might expect to have mothers or other female relatives attend to their labors and deliveries. The woman's mother might not be in this country. If the mother (or another female relative) is available, she might not speak English, and she might have different ideas about the best care for her daughter. The new mother might struggle, as she is likely to have a low level of understanding of the childbirth process, her own postpartum care, and early infant care. It is likely that the man will have no understanding of these processes and believe it is not his place to be involved. The Indian woman and her husband might find it difficult or unacceptable to have her attended by a male physician.

Most often in the United States, the woman and her physician discuss birth control options. In the case of the Indian patient, it is important for the physician to ask the married woman if contraception should be discussed first between the physician and her husband. It might be more appropriate to discuss birth control options with the patient's husband alone and respect his decision for the couple. The physician might want to ask the husband for his permission to discuss birth control with his wife.

We discuss some of the issues that can arise while caring for an Indian woman in the US health care system. A lack of understanding of the Indian cultural mores surrounding sexual education, sexual behavior, and the childbirth experience could form barriers for Indian immigrants in need of health care. These misunderstandings can also lead to patient dissatisfaction with the health provider and health system, underutilization of health services, and poorer health outcomes for Indian immigrants and their families. ${ }^{3}$ For this reason it is important to teach cultural issues during undergraduate, ${ }^{15}$ graduate $^{16}$ and continuing medical education. ${ }^{3}$

\section{References}

1. US Bureau of Census. Resident population of the United States: estimates by sex, race, and Hispanic origin, with median age. December 28, 1998. Available at: http://www.census.gov/populations/ estimates/nation/intfile3-1.txt.

2. Flores G. Culture and the patient-physician relationship: achieving cultural competency in health care. J Pediatr 2000;136:14-23.

3. Nunez A. Transforming cultural competence into cross-cultural efficacy in women's health education. Acad Med 2000;75:1071-80.

4. Immigration and Naturalization Service population statistics, March 7, 2000, report. Available at: http:// www.ins.usdoj.gov/graphics/aboutins/statistics/299. htm.

5. Aggarwal O, Sharma AK, Chhabra P. Study in sexuality of medical college students in India. J Adolesc Health 2000;26:226-9.

6. Caldwell JC, Caldwell P, Caldwell BK, Pieris I. The construction of adolescence in a changing world: implications for sexuality, reproduction, and marriage. Stud Fam Plann 1998;29:137-53.

7. Mudd JW, Siegel RJ. Sexuality-the experience and anxieties of medical students. N Engl J Med1 1969; 281:1397-403.

8. Nathawat SS, Mathur A. Marital adjustment and subjective well-being in Indian-educated housewives and working women. J Psychol 1993;127:353-8.

9. Waldner L, Vaden-Goad L, Sikka A. Sexual coercion in India: an exploratory analysis using demographic variables. Arch Sex Behav 1999;28:523-38.

10. Sarin A. India: the "male factor" in women's reproductive ill-health. Women's Intl Network News 2000;26(1):19.

11. Nath DC, Land KC, Goswami G. Effects of the status of women on the first-birth interval in Indian urban society. J Biosoc Sci 1999;31:55-69.

12. Sinha M. "Nationalism and respectable sexuality in India." Genders 1995;Spring(21):30-57.

13. Jancin B. Unconsummated marriage: helping couples close the deal. Fam Pract News 2001;Oct 1:18.

14. Friedman LJ. Virgin wives: a study of unconsummated marriages. London: Tavistock Publications, 1957.

15. Flores G, Gee D, Kastner B. The teaching of cultural issues in U.S. and Canadian medical schools. Acad Med 2000;75:451-5.

16. Markakis KM, Beckman HB, Suchman AL, Frankel RM. The path to professionalism: cultivating humanistic values and attitudes in residency training. Acad Med 2000;75:141-50. 